\title{
Single nucleotide polymorphisms in the apolipoprotein B and low density lipoprotein receptor genes affect response to antihypertensive treatment
} \author{
Ulrika Liljedahl*1, Lars Lind ${ }^{1,4}$, Lisa Kurland1 ${ }^{1}$, Lars Berglund ${ }^{2}$, \\ Thomas Kahan ${ }^{3}$ and Ann-Christine Syvänen ${ }^{1}$
}

Address: ${ }^{1}$ Department of Medical Sciences, Uppsala University, Uppsala University Hospital, Entrance 70, 3rd floor, 75185 Uppsala, Sweden, ${ }^{2}$ Uppsala Clinical Research Center (UCR), Uppsala University, 75185 Uppsala, Sweden, ${ }^{3}$ Division of Internal Medicine, Karolinska Institute, Danderyd Hospital, 18288 Stockholm, Sweden and ${ }^{4}$ Astra Zeneca Research \& Development Mölndal, 43183 Mölndal, Sweden

Email: Ulrika Liljedahl* - Ulrika.Liljedahl@medsci.uu.se; Lars Lind - Lars.Lind@medsci.uu.se; Lisa Kurland - Lisa.Kurland@medsci.uu.se; Lars Berglund - Lars.Berglund@ucr.uu.se; Thomas Kahan - Thomas.Kahan@med.ds.sll.se; Ann-Christine Syvänen - Ann-

Christine.Syvanen@medsci.uu.se

* Corresponding author

Published: 28 September 2004

BMC Cardiovascular Disorders 2004, 4:16 doi:10.1 186/147|-226I-4-16

This article is available from: http://www.biomedcentral.com/|47|-226//4/16

(c) 2004 Liljedahl et al; licensee BioMed Central Ltd.

This is an open-access article distributed under the terms of the Creative Commons Attribution License (http://creativecommons.org/licenses/by/2.0), which permits unrestricted use, distribution, and reproduction in any medium, provided the original work is properly cited.

\begin{abstract}
Background: Dyslipidemia has been associated with hypertension. The present study explored if polymorphisms in genes encoding proteins in lipid metabolism could be used as predictors for the individual response to antihypertensive treatment.
\end{abstract}

Methods: Ten single nucleotide polymorphisms (SNP) in genes related to lipid metabolism were analysed by a microarray based minisequencing system in DNA samples from ninety-seven hypertensive subjects randomised to treatment with either $150 \mathrm{mg}$ of the angiotensin II type I receptor blocker irbesartan or $50 \mathrm{mg}$ of the $\beta_{1}$-adrenergic receptor blocker atenolol for twelve weeks.

Results: The reduction in blood pressure was similar in both treatment groups. The SNP C7IIT in the apolipoprotein $\mathrm{B}$ gene was associated with the blood pressure response to irbesartan with an average reduction of $19 \mathrm{mmHg}$ in the individuals carrying the C-allele, but not to atenolol. The CI6730T polymorphism in the low density lipoprotein receptor gene predicted the change in systolic blood pressure in the atenolol group with an average reduction of $14 \mathrm{mmHg}$ in the individuals carrying the $\mathrm{C}$-allele.

Conclusions: Polymorphisms in genes encoding proteins in the lipid metabolism are associated with the response to antihypertensive treatment in a drug specific pattern. These results highlight the potential use of pharmacogenetics as a guide for individualised antihypertensive treatment, and also the role of lipids in blood pressure control. 


\section{Background}

Hypertension is a complex trait caused by multiple environmental and genetic factors interacting through the cardiac, vascular and endothelial systems. Several drug classes with different mechanisms of action, including inhibitors of the renin-angiotensin-aldosterone system (RAAS), calcium channel blockers, adrenergic receptor blockers and diuretics, are available for treatment of hypertension. However, the response to antihypertensive treatment is highly variable between individuals, which makes it difficult to predict the efficacy of a specific drug in the individual patient [1-3]. Currently, there are no clinically useful biochemical or metabolic markers for predicting the individual responses to antihypertensive treatment [4-6].

Twin studies have estimated that as much as half of the variability in blood pressure levels between individuals is due to genetic factors $[7,8]$. Based on the abundance of single nucleotide polymorphisms (SNPs) in the human genome [9], it can be expected that one or more SNPs occur in each of the genes encoding components of the blood pressure regulating systems, and that they are the genetic factors influencing individual blood pressure levels. Coding SNPs affecting the function of enzymes and receptors in pathways of blood pressure regulation, or regulatory SNPs, affecting the expression levels of genes, are likely to explain part of the variability of the response to antihypertensive treatment. Hence, these functional SNPs, or other SNPs inherited in linkage disequilibrium with them, could be potential pharmacogenetic markers for predicting the response to a certain drug, and thus guide the selection of the optimal drug for each individual patient [10-12].

The RAAS and the sympathetic nervous system play key roles in blood pressure regulation. We have earlier shown that polymorphisms in the angiotensin converting enzyme gene [13] and a SNP in the aldosterone synthase gene [14] are related to changes in blood pressure during treatment with the angiotensin II receptor blocker irbesartan, whereas two SNPs in the angiotensinogen gene were associated to the reduction in blood pressure by the $\beta_{1}$-adrenergic receptor blocker atenolol [15]. Dyslipidemia with high levels of serum triglycerides and free fatty acids, and elevated serum cholesterol levels and low levels of high-density lipoprotein cholesterol are common in hypertensive patients. Association has been found between disturbance in lipid metabolism and hypertension, but so far no attempts have been made to relate variables reflecting lipids, or the genes involved in lipid metabolism, to the individual response to antihypertensive treatment.
We have recently developed a microarray based minisequencing system for parallel genotyping of multiple SNPs in blood pressure regulating candidate genes [16]. Here we analysed the relationships between the genotypes of SNPs in the apolipoprotein A-IV, apolipoprotein A-V, apolipoprotein B-100, low density lipoprotein receptor, hepatic lipase and lipoprotein genes and reductions in blood pressure in hypertensive patients randomised to monotherapy with either irbesartan or atenolol. We found that SNP alleles in the apolipoprotein B gene and the low density lipoprotein receptor gene were associated to the antihypertensive response after twelve weeks of treatment.

\section{Methods \\ Study population}

DNA extracted from blood samples from 97 hypertensive patients from the double blind parallel group "Swedish Irbesartan Left Ventricular Hypertrophy Investigation versus Atenolol" (SILVHIA) trial [17] were analysed. Men and women above the age of 18 , having primary mild to moderate hypertension and left ventricular hypertrophy were enrolled in the trial and randomised to receive either $150 \mathrm{mg}$ of the angiotensin II type 1 receptor blocker irbesartan or $50 \mathrm{mg}$ of the $\beta_{1}$-adrenergic receptor blocker atenolol once daily as monotherapy. The dose was doubled after six weeks if the diastolic blood pressure was $\geq 90$ $\mathrm{mmHg}$. Blood pressure was measured by trained nurses using a mercury sphygmomanometer, after the patients had rested for at least $10 \mathrm{~min}$ in the seated position. Left ventricular hypertrophy was defined as left ventricular mass index of $>131 \mathrm{~g} / \mathrm{m}^{2}$ for men and $>100 \mathrm{~g} / \mathrm{m}^{2}$ for women, assessed by echocardiography. The data presented relates to the change in blood pressure after 12 weeks of treatment. For details on the SILVHIA trial, see Malmqvist etal [17]. Baseline characteristics for the patients are presented in Table 1 . The study was approved by the ethics committees of all participating centres of the SILVHIA trial and that of the Medical Faculty of Uppsala University.

\section{SNP markers and genotyping procedure}

In our previous study [16], 98 SNPs were selected from the NCBI (dbSNP, http://www.ncbi.nlm.nih.gov/SNP) and the SNP Consortium (TSC, http://snp.cshl.org) databases and validated in a pooled DNA sample representing the Swedish population. A subset of these SNPs located in genes involved in lipid metabolism and that were polymorphic in the Swedish population were included in the study presented here, together with one additional SNP in the apolipoprotein A-V gene. See Table 2 for information on the SNPs.

Fragments comprising the SNPs were amplified in multiplex PCR described previously [16]. A microarray based 
Table I: Characteristics of the hypertensive patients in the two treatment groups.

\begin{tabular}{lcc}
\hline & Irbesartan group $^{2}$ & Atenolol group $^{2}$ \\
\hline Number of patients & 48 & 49 \\
Age (years) & $54 \pm 8$ & $54 \pm 8$ \\
Gender (proportion females) & $37 \%$ & $31 \%$ \\
Height (m) & $1.74 \pm 0.09$ & $1.73 \pm 0.09$ \\
Weight $(\mathrm{kg})$ & $83 \pm 15$ & $82 \pm 14$ \\
Smokers trial start (\%) & 29 & 18 \\
Baseline fs-cholesterol (mM) & $6.1 \pm 1.0$ & $5.8 \pm 1.1$ \\
Baseline fb-glucose $(\mathrm{mM})$ & $5.7 \pm 3.1$ & $5.2 \pm 2.5$ \\
Pre-treatment SBPI (mmg) & $164 \pm 18$ & $160 \pm 20$ \\
Pre-treatment DBPI (mmHg) & $104 \pm 7$ & $103 \pm 8$ \\
Change in SBP at I2 weeks (mmHg) & $-16 \pm 20$ & $-11 \pm 16$ \\
Change in DBP at I2 weeks (mmHg) & $-9.0 \pm 11$ & $-12 \pm 7.7$
\end{tabular}

I Systolic blood pressure (SBP) and diastolic blood pressure (DBP)

2 Data are mean \pm SD

Table 2: Investigated polymorphisms given as gene names, acronym and GenBank accession number.

\begin{tabular}{|c|c|c|c|}
\hline Gene name and acronym ${ }^{\prime}$ & dbSNP ID ${ }^{2}$ & Amino acid alteration & SNP name 3 \\
\hline Apolipoprotein A-IV & rs5092 & Thr/Thr & Al449G \\
\hline \multicolumn{4}{|l|}{ APOA-IV; J02758 } \\
\hline Apolipoprotein A-V & rs662799 & Promoter & $\mathrm{C} 31455 \mathrm{~T}$ \\
\hline \multicolumn{4}{|l|}{ APOA-V; AC074203 } \\
\hline Apolipoprotein B-100 & rs 1801701 & Arg/Gln & GI0I08At \\
\hline APOB; MI9828+; MI98I0§ & rs 1367117 & Thr/lle & C7IIT§ \\
\hline Low density lipoprotein receptor & rs688 & Asn/Asn & $\mathrm{Cl} 6730 \mathrm{~T}$ \\
\hline LDLR; AF2I7403 & rs5925 & Val/Val & C2000IT \\
\hline Lipase, hepatic & rs 6083 & Asn/Ser & AIIOG \\
\hline \multicolumn{4}{|l|}{ LIPC; M35429 } \\
\hline Lipoprotein & rs328 & Ser/Term & C9040G \\
\hline \multirow[t]{2}{*}{ LPL; AF050I63 } & rs312 & Intron & G73I5C \\
\hline & rs314 & Intron & A7360G \\
\hline
\end{tabular}

I Gene name and acronym, GenBank accession number http://www.ncbi.nlm.nih.gov/ for the sequence used in the design of primers for the PCR and minisequencing reactions.

2 SNP identification number in the NCBI SNP database dbSNP, http://www.ncbi.nlm.nih.gov/SNP.

${ }_{3}^{3}$ Corresponding to the nucleotide position in the gene sequence referenced in the first column and the nucleotide variation in the coding strand.

minisequencing single nucleotide primer extension assay, in which one or two of four ddNTPs labelled with the fluorophore Tamra (Perkin Elmer Life Sciences, Boston, MA, USA) were incorporated by the Thermo Sequenase ${ }^{\mathrm{TM}}$ DNA-polymerase at each SNP site. The incorporated ddNTPs were detected using a fluorescence scanner, and the fluorescence signals were extracted. A signal intensity fraction, obtained by dividing the fluorescence signal intensity for allele 1 with the sum of the fluorescence signal intensities for allele 1 and allele2, was used to assign the individual genotypes. The SNP APOA-V C31455T was genotyped using a microtiter plate minisequencing assay with tritium detection [18].

\section{Statistical analyses}

Analysis of covariance (ANCOVA) with each SNP as factor, baseline blood pressure as covariate and the change in blood pressure as response, was performed. The analyses were performed by treatment group and blood pressure measurement (systolic and diastolic blood pressures). Correction for multiple testing was performed by calculation of critical p-values corresponding to a nominal type I 
error of 5\% using a permutation test [19]. Two tailed significance levels were used.

\section{Results and discussion}

We explored possible associations between individual genotypes of ten SNPs and reduction in systolic and diastolic blood pressure as response to treatment with atenolol or irbesartan (Figure 1) in samples from the SILVHIA trial [17]. In the irbesartan group, a change in systolic blood pressure appeared to be related to genotype for the SNPs ApoA-IV A1449G, ApoA-V C31455T and ApoB $\mathrm{C} 711 \mathrm{~T}$. In the atenolol treatment group, presence of the C-allele of the SNP LDLR C16730T was associated to the reduction in systolic blood pressure.

Correction for multiple testing using a permutation test [19] yielded critical p-values of 0.004 and 0.007 for systolic blood pressure after atenolol and irbesartan treatment, respectively, and 0.006 and 0.007 for the diastolic blood pressure, corresponding to the significance level of $\mathrm{p}=$ 0.05. After the permutation test, carriership of the C-allele of the C711T SNP in the apolipoprotein $\mathrm{B}$ gene remained significantly associated to the reduction in systolic blood pressure $(\mathrm{p}=0.004)$ in the irbesartan treatment group (Figure 1) while the individuals homozygous for the Tallele showed no reduction in systolic blood pressure. The same pattern of response related to genotype was seen for diastolic blood pressure, although it did not reach statistical significance. In the atenolol treatment group, the SNP C16730T in the low density lipoprotein receptor gene showed a trend of association to the reduction in systolic blood pressure. Presence of the $\mathrm{C}$-allele was related to blood pressure reduction ( $\mathrm{p}=0.006)$, while the individuals homozygous for the T-allele $(n=9)$ actually showed an increase in systolic blood pressure (Figure 1). A similar response pattern was not seen for the diastolic blood pressure during atenolol treatment $(\mathrm{p}=0.44)$ (Figure 1$)$. There were 39 carriers of the favourable $\mathrm{C}$-allele of the $\mathrm{APOB}$ C711T SNP in the irbesartan treatment group. The average reduction in systolic blood pressure for these individuals was $19 \mathrm{mmHg}$, compared to $0 \mathrm{mmHg}$ for the individuals lacking this allele. In the atenolol treatment group, the individuals carrying the favourable C-allele of the SNP LDLR C16730T showed an average reduction of 14 $\mathrm{mmHg}$ in systolic blood pressure compared to an increase of $7.5 \mathrm{mmHg}$ for the individuals homozygous for the Tallele.

The SNP C711T in the apolipoprotein B gene is located in the coding region of the gene, and alters a threonine residue to an isoleucine residue in the protein. This SNP is located in the amino-terminal part of the enzyme and has been suggested to affect the dimerisation of apolipoprotein $\mathrm{B}$ and low density lipoprotein during cholesterol transport [20]. The C16730T SNP in the LDLR gene results in a synonymous amino acid change, however this SNP could be in linkage disequilibrium with another functional SNP potentially influencing the response to drug treatment. Irrespectively if the tested SNPs are actually functional, our findings imply a potential connection between lipid metabolism and response to antihypertensive treatment.

We have recently found circulating apolipoprotein B to be the most powerful predictor of endothelium-dependent vasodilation of the commonly used markers of cholesterol metabolism [21]. It is not evident, however, why apolipoproteins predict the response to irbesartan, and not to atenolol treatment, as these drugs appear to improve endothelium-dependent vasodilation to a similar extent [22]. Lipid abnormalities, commonly seen in hypertension, have been considered to be connected to the blood pressure level by the common denominators obesity and insulin resistance. Other studies have suggested a more direct effect of lipids in blood pressure control, as infusion of the fat emulsion Intralipid together with heparin increases blood pressure in healthy subjects [23-25]. This effect is more pronounced in the normotensive subjects with a family history of hypertension [26]. It has also been shown that an acute elevation of free fatty acids alters heart rate variability, an index of cardiac autonomic nervous system balance [27], suggesting that lipid metabolism may be involved in the regulation of cardiovascular autonomic tone. Thus our results that indicate involvement of components of lipid metabolism in the response to antihypertensive treatment are supported by cross-sectional epidemiological studies.

In our earlier exploratory study, 74 SNPs with a minor allele frequency over 5\%, including nine of the SNPs analysed here were tested as predictors of blood pressure regulation in the SILVHIA study samples using a multiple regression model [16]. The main aim of this study was to establish the microarray-based genotyping system. Analysis of twenty-eight SNPs from this panel that are located in genes from the renin-angiotensin aldosterone system identified a SNP in the aldosterone synthase gene (CYP11B2 T267C) and two SNPs in the angiotensinogen gene (AGT G1218A and T1198C) that appeared to be associated to blood pressure reduction $[14,15]$. A limitation in these previous studies was that correction for multiple testing was not applied, whereas in the current study we used a permutation test.

A remaining weakness in our study is the small number of samples available for analysis, which does not allow detection of small to medium size gene effects, and results in uncertain estimation of the the magnitude of the effects detected. Moreover, in a small study there is the risk of a non-representative group of patients with respect to 


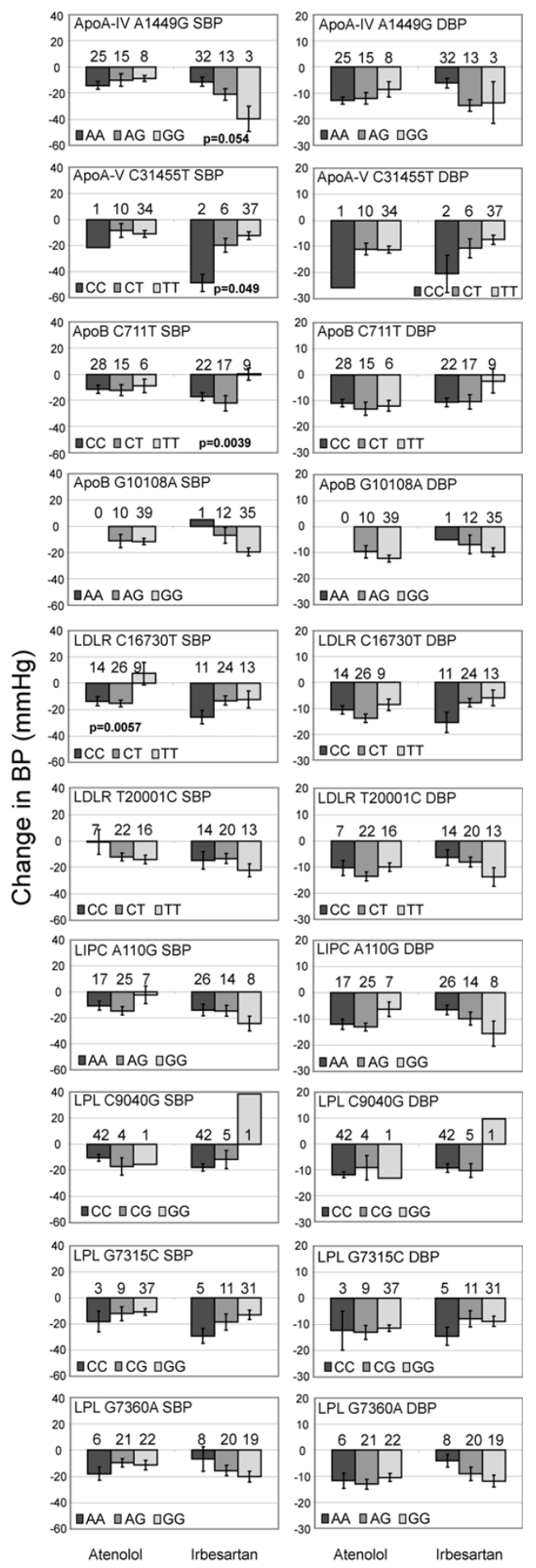

Figure I

Effect of SNP genotype on the change in blood pressure after 12 weeks of treatment for the ten SNPs. For each of the SNPs, the pattern of change in blood pressure related to genotype is illustrated for the systolic blood pressure (SBP) and diastolic blood pressure (DBP) in separate panels. In each panel, the mean change in blood pressure is shown for the SNP genotypes in the atenolol treatment group on the left, and the corresponding results in the irbesartan treatment group are given on the right. The error bars corresponds to the standard error of the mean. The p-values indicating significance for the APOA-IV A I449G, APOA-V C3I455T, APOB C7IIT and LDLR CI6730T SNPs are given in the corresponding panels. The number of individuals of each genotype is shown above the bars in each panel. 
gender, age, and genotype distribution. Despite these limitations, we detected a significant effect of the SNP C711T in the apolipoprotein B gene and the SNP C16730T in the low density lipoprotein receptor after correction for multiple testing. The pharmacogenetically interesting results from our study need to be replicated in other studies.

As the C711T SNP in the apolipoprotein B gene predicted response to treatment with irbesartan, and the C16730T SNP in the low density lipoprotein receptor gene appeared to predict response to atenolol treatment, our results point at possible use of SNPs in genes encoding components of lipid metabolism in pharmacogenetic panels for selecting the optimal drug for each patient. To our knowledge our study is the first one to investigate the relationship between polymorphisms in genes involved in lipid metabolism and the response to antihypertensive treatment.

\section{Competing interests}

The authors declare that they have no competing interests.

\section{Authors' contributions}

UL performed the development of genotyping technology, genotyping lab work, interpretation of data and had a substantial role in writing the manuscript. LL provided clinical expertise, participated in selection of candidate genes and contributed to writing. LK provided clinical expertise, established a database of the SILVHIA phenotypes, and in writing. LB performed the statistical analysis. TK provided the SILVHIA samples and contributed to writing the manuscript. A-CS contributed by planning and supervision of the project, and to writing the manuscript.

\section{Acknowledgements}

Financial support for this study was provided by the Swedish Research Council and the K\&A Wallenberg foundation (WCN) (A-C S) and the Karolinska Institute, Stockholm (T K).

\section{References}

I. Cadman PE, O'Connor DT: Pharmacogenomics of hypertension. Curr Opin Nephrol Hypertens 2003, I 2:61-70.

2. Turner ST, Schwartz GL, Chapman AB, Hall WD, Boerwinkle E: Antihypertensive pharmacogenetics: getting the right drug into the right patient. J Hypertens 200I, 19:I-II.

3. Turner ST, Boerwinkle E: Genetics of blood pressure, hypertensive complications, and antihypertensive drug responses. Pharmacogenomics 2003, 4:53-65.

4. Laragh JH, Lamport B, Sealey J, Alderman MH: Diagnosis ex juvantibus. Individual response patterns to drugs reveal hypertension mechanisms and simplify treatment. Hypertension 1988, I 2:223-226.

5. Lind L, Berne $C$, Andersson PE, Hanni A, Lithell $\mathrm{H}$ : Is insulin resistance a predictor of the blood pressure response to antihypertensive treatment? J Hum Hypertens 1995, 9:759-763.

6. Koopmans RP, Insel PA, Michel MC: Pharmacogenetics of hypertension treatment: a structured review. Pharmacogenetics 2003, 13:705-7|3.

7. Pausova Z, Gossard F, Gaudet D, Tremblay J, Kotchen TA, Cowley AW, Hamet P: Heritability estimates of obesity measures in siblings with and without hypertension. Hypertension 200I, 38:41-47.

8. Fagard RH, Loos RJ, Beunen G, Derom C, Vlietinck R: Influence of chorionicity on the heritability estimates of blood pressure: a study in twins. J Hypertens 2003, 21:1313-1318.

9. Sachidanandam R, Weissman D, Schmidt SC, Kakol JM, Stein LD, Marth G, Sherry S, Mullikin JC, Mortimore BJ, Willey DL, Hunt SE, Cole CG, Coggill PC, Rice CM, Ning Z, Rogers J, Bentley DR, Kwok PY, Mardis ER, Yeh RT, Schultz B, Cook L, Davenport R, Dante M, Fulton L, Hillier L, Waterston RH, McPherson JD, Gilman B, Schaffner S, Van Etten WJ, Reich D, Higgins J, Daly MJ, Blumenstiel B, Baldwin J, Stange-Thomann N, Zody MC, Linton L, Lander ES, Attshuler D: A map of human genome sequence variation containing 1.42 million single nucleotide polymorphisms. Nature 200I, 409:928-933.

10. Cardon LR, Idury RM, Harris TJ, Witte JS, Elston RC: Testing drug response in the presence of genetic information: sampling issues for clinical trials. Pharmacogenetics 2000, 10:503-510.

II. Bader JS: The relative power of SNPs and haplotype as genetic markers for association tests. Pharmacogenomics 200I, 2:II-24.

12. Doris PA: Hypertension genetics, single nucleotide polymorphisms, and the common disease:common variant hypothesis. Hypertension 2002, 39:323-331.

13. Kurland L, Melhus H, Karlsson J, Kahan T, Malmqvist K, Ohman KP, Nystrom F, Hagg A, Lind L: Angiotensin converting enzyme gene polymorphism predicts blood pressure response to angiotensin II receptor type I antagonist treatment in hypertensive patients. J Hypertens 2001, 19:1783-1787.

14. Kurland L, Melhus H, Karlsson J, Kahan T, Malmqvist K, Ohman P, Nystrom F, Hagg A, Lind L: Aldosterone synthase (CYP I I B2) $344 \mathrm{C} / \mathrm{T}$ polymorphism is related to antihypertensive response: result from the Swedish Irbesartan Left Ventricular Hypertrophy Investigation versus Atenolol (SILVHIA) trial. Am J Hypertens 2002, 15:389-393.

15. Kurland L, Liljedahl U, Karlsson J, Kahan T, Malmqvist K, Melhus H, Syvanen AC, Lind L: Angiotensinogen gene polymorphisms: relationship to blood pressure response to antihypertensive treatment. Results from the Swedish Irbesartan Left Ventricular Hypertrophy Investigation vs Atenolol (SILVHIA) trial. Am J Hypertens 2004, 17:8-13.

16. Liljedahl U, Karlsson J, Melhus H, Kurland L, Lindersson M, Kahan T, Nystrom F, Lind L, Syvanen AC: A microarray minisequencing system for pharmacogenetic profiling of antihypertensive drug response. Pharmacogenetics 2003, 13:7-17.

17. Malmqvist K, Kahan T, Edner M, Held C, Hagg A, Lind L, Muller-Brunotte R, Nystrom F, Ohman KP, Osbakken MD, Ostergern J: Regression of left ventricular hypertrophy in human hypertension with irbesartan. J Hypertens 2001, 19:1 I67-II76.

18. Syvanen AC, Sajantila A, Lukka M: Identification of individuals by analysis of biallelic DNA markers, using PCR and solid-phase minisequencing. Am J Hum Genet 1993, 52:46-59.

19. Churchill GA, Doerge RW: Empirical threshold values for quantitative trait mapping. Genetics 1994, I38:963-97I.

20. Chatterton JE, Schlapfer P, Butler E, Gutierrez MM, Puppione DL, Pullinger CR, Kane JP, Curtiss LK, Schumaker VN: Identification of apolipoprotein B 100 polymorphisms that affect low-density lipoprotein metabolism: description of a new approach involving monoclonal antibodies and dynamic light scattering. Biochemistry 1995, 34:957|-9580.

21. Steer P, Hulthe J, Miligard J, Sarabi DM, Basu S, Vessby B, Lind L: Endothelial vasodilatory function is predicted by circulating apolipoprotein B and HDL in healthy humans. Lipids 2002, 37: I I35-II 40.

22. von zur Muhlen B, Kahan T, Hagg A, Millgard J, Lind L: Treatment with irbesartan or atenolol improves endothelial function in essential hypertension. J Hypertens 2001, 19:1813-1818.

23. Stepniakowski KT, Goodfriend TL, Egan BM: Fatty acids enhance vascular alpha-adrenergic sensitivity. Hypertension 1995, 25:774-778.

24. Haastrup AT, Stepniakowski KT, Goodfriend TL, Egan BM: Intralipid enhances alphal-adrenergic receptor mediated pressor sensitivity. Hypertension 1998, 32:693-698.

25. Stojiljkovic MP, Zhang D, Lopes HF, Lee CG, Goodfriend TL, Egan BM: Hemodynamic effects of lipids in humans. Am J Physiol Regul Integr Comp Physiol 200I, 280:R I674-9. 
26. Lopes HF, Stojiljkovic MP, Zhang D, Goodfriend TL, Egan BM: The pressor response to acute hyperlipidemia is enhanced in lean normotensive offspring of hypertensive parents. Am J Hypertens 200I, 14:1032-1037.

27. Stepniakowski KT, Sallee FR, Goodfriend TL, Zhang Z, Egan BM: Fatty acids enhance neurovascular reflex responses by effects on alpha I-adrenoceptors. Am J Physiol 1996, 270:RI340-6.

\section{Pre-publication history}

The pre-publication history for this paper can be accessed here:

http://www.biomedcentral.com/1471-2261/4/16/prepub

Publish with Bio Med Central and every scientist can read your work free of charge

"BioMed Central will be the most significant development for disseminating the results of biomedical research in our lifetime. " Sir Paul Nurse, Cancer Research UK

Your research papers will be:

- available free of charge to the entire biomedical community

- peer reviewed and published immediately upon acceptance

- cited in PubMed and archived on PubMed Central

- yours - you keep the copyright

Submit your manuscript here:

http://www.biomedcentral.com/info/publishing_adv.asp 